\title{
Airway Resistance, Airway Conductance, Specific Airway Resistance, and Specific Airway Conductance in Children
}

\author{
M. LEBEN ${ }^{(31)}$ AND H. VON DER HARDT \\ Children's Hospital of the Medical School of Hannover, Division of Pediatric Pneumology [H. von der Hardt], \\ D-3000 Hannover, Federal Republic of Germany
}

\begin{abstract}
Summary
In 82 healthy children and in asthmatic children before and during positive allergen provocation test, airway resistance $\left(\mathbf{R}_{\mathrm{aw}}\right)$, airway conductance $\left(G_{\mathrm{aw}}\right)$, specific airway resistance $\left(\mathbf{S R}_{\mathrm{aw}}\right)$, and specific airway conductance $\left(\mathbf{S G}_{\mathrm{aw}}\right)$ were measured by body plethysmography during quiet breathing. $R_{\text {aw }}$ over total flow range

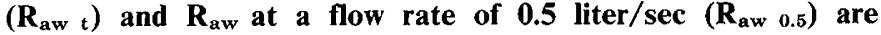
compared: $R_{a w} 0.5$ is $10.3 \%$ smaller and shows a smaller coefficient of variation in healthy children. This is interpreted as a less important influence of variations of glottis opening. $\mathbf{S R}_{\mathrm{aw}} \mathrm{t}$ mean value is $7.08 \mathrm{hPa} \cdot \mathrm{sec} ; \mathrm{SG}_{\text {aw } t}$ mean value is $0.141 \mathrm{hPa}^{-1} \cdot \mathrm{sec}^{-1}$. In asthmatic children, $\mathbf{R}_{\mathrm{aw} 0.5}$ proves to be a more sensitive parameter for the evaluation of inhalation provocation tests than $R_{a w}$. The most sensitive indices of obstruction in the central and more peripheral bronchi are $\mathbf{S R}_{\mathrm{aw} 0.5}$ and $\mathrm{SG}_{\mathrm{aw} 0.5}$.
\end{abstract}

\section{Abbreviations}

BTPS, body temperature and ambient pressure saturated with water vapor

$\mathrm{FRC}_{\text {box }}$, functional residual capacity measured by body plethysmography

$G_{\text {aw }}$, airway conductance

hPa, hecto Pascal

$\Delta \mathbf{P}_{\mathrm{M}}$, pressure at the mouth

$\mathbf{R}_{\mathrm{aw}}$, airway resistance

$\mathbf{R}_{\mathrm{aw}}$, , terminal airway resistance

$\mathrm{SG}_{\mathrm{aw}}$, specific airway resistance

$\mathrm{SR}_{\text {aw }}$, specific airway resistance over total flow range

$\operatorname{tg} \alpha, \Delta V_{b} / \Delta P_{M}$

$\dot{\mathrm{V}}$, airflow

$\Delta V_{b}$, volume displacement

$\Delta V_{M}$, tidal volume

The development of body plethysmography has furnished a noninvasive method of assessing $R_{a w}$. $R_{a w}$ is defined as the ratio of alveolar pressure to air flow. Usually, the pressure or volume changes of the plethysmograph corresponding to alveolar pressure are plotted versus air flow. $R_{a w}$ is then calculated from the slope of the resulting S-shaped curve. DuBois and co-workers (8) measured $R_{a w}$ at a certain flow rate on the linear part of the curve during panting. After the problem of maintaining BTPS conditions in the breathing air was solved, many investigators turned to measuring $R_{a w}$ during quiet breathing instead of panting. It was then proposed to measure $R_{a w}$ over the total range of alveolar pressure ("total $R_{a w}$ ", 26 ) or over the points of maximum inspiratory and expiratory air flow $(23,20)$. For the latter way of interpretation, Haluszka (13) suggested the term "terminal $\mathrm{R}_{a w}$ " $\left(R_{a w} t\right)$ because the terminal points of the curve are used. At present, there seem to be mainly two groups of investigators: those who measure $R_{a w}$ at fixed flow rates during panting and those who measure $\mathrm{R}_{\mathrm{aw}}$ at maximum flow during quiet breathing.

It is the aim of the present study to compare the fixed flow and the "terminal" $R_{a w}$ interpretation applied to the same measurements during quiet breathing in healthy and in asthmatic children.

\section{MATERIALS AND METHODS}

Measurements of $\mathrm{FRC}_{\mathrm{box}}$ and of $\mathrm{R}_{\mathrm{aw}}$ were performed in an air conditioned pressure-corrected volume displacement whole-body plethysmograph (29). The technical details have been described previously (15). The electronic signals for volume displacement (integrated and pressure-corrected flow signal) of the body plethysmograph $\left(\Delta \mathrm{V}_{\mathrm{b}}\right), \Delta \mathrm{P}_{\mathrm{M}}, \dot{\mathrm{V}}$, and its integral, $\Delta \mathrm{V}_{\mathrm{M}}$, were stored simultaneously on a magnetic tape and played back at a lower speed on an X/Y recorder (30). The breathing air was kept at body temperature and water vapour saturated in a 601 -Douglas bag. For inhalation challenges, the additional equipment described by von der Hardt and co-workers (15) was used.

The investigation was performed in 82 school children ( 47 boys and 35 girls with comparable distribution of standing height), age 6-15 years, with the consent of their parents. Medical history and physical examination did not reveal any respiratory disease. In addition, inhalation provocation tests taken for clinical purpose from six asthmatic children (four boys and two girls, age 9-14 years, standing height $136-162 \mathrm{~cm}$ ) were analysed. Measurements were taken in the sitting position, the nose closed by a nose clip. The following measurements and calculations were performed.

(1) In 76 of the 82 children (43 boys and 33 girls) $\mathrm{FRC}_{\text {box }}$ was calculated from $\operatorname{tg} \alpha$ of the $\Delta \mathrm{V}_{\mathrm{b}} / \Delta \mathrm{P}_{\mathrm{M}}$ diagram obtained by the Pflüger maneuver (20). Final values were corrected for the deadspace volume of the mouthpiece and the shutter $(0.11 \mathrm{l})$ and for deviation from the end-expiratory level detected by the spirogram recorded simultaneously. In the remaining six children, the latter correction was not exactly possible because the spirogram did not show a sufficient number of respiratory cycles preceeding the close of the shutter. $\operatorname{tg} \alpha$ was used only to calculate $\mathbf{R}_{\mathrm{aw}}$ if the shutter was closed within the lower third of the tidal volume.

(2) In 82 children, resistance curves $\left(\Delta \mathbf{V}_{\mathrm{b}} / \dot{\mathrm{V}}\right.$ diagrams $)$ were recorded during quiet breathing. BTPS conditions were checked by the $\Delta \mathrm{V}_{\mathrm{b}} / \Delta \mathrm{V}_{\mathrm{M}}$ loops (20). $\mathrm{R}_{\mathrm{aw}}$ was calculated in two different ways. $(A)$ In all children, $\mathrm{R}_{\mathrm{aw}} \mathrm{t}$ was calculated from the slope of the line connecting the points of maximum inspiratory and expiratory flow in the $\Delta V_{b} / \dot{V}$ diagram (Fig. 1). (B) In 46 of the 82 children ( 28 boys and 18 girls), $R_{a w}$ was also calculated from the slope of the line connecting the points at an inspiratory and expiratory flow of 0.5 liter/sec $\left(R_{a w} 0.5\right)$. If there was a difference in $\Delta V_{b}$ at the level of 0.5 liter/sec, the bisecting points of the $\Delta V_{b}$ difference at this level were used (Fig. 1).

$R_{a w}$ was determined as the mean of three to five successive and nonselected respiratory cycles according to the formula by Mat- 
thys (20). The airflow resistance of the apparatus $(0.5 \mathrm{hPa} /$ liter/ sec) was subtracted.

In three of the taller boys, it was not possible to determine $R_{a w} 0.5$ for technical reasons (the zero line for $\dot{V}$ was not registrated). The remaining 33 of the 82 children (34\% of the boys and $49 \%$ of the girls) did not reach a sufficient air flow for this calculation during quiet breathing. This did not only pertain to smaller children, but also to taller ones; however, the \% of children not reaching sufficient flow rates decreased with increasing standing height. Most of the lacking flow rates were around or slightly below 0.5 liter/sec. The distributions of standing height in the two groups of different $\mathbf{R}_{\mathrm{aw}}$ calculation compare well (Fig. 2).

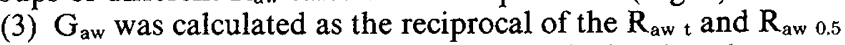
values. In this study, $G_{a w}$ values were not calculated as the mean of the reciprocals of $R_{a w}$ of different respiratory cycles, but as the reciprocal of the mean, in order to avoid overestimation of $\mathrm{G}_{\mathrm{aw}}$ (4).

(4) $\mathrm{SR}_{\mathrm{aw}}$ was calculated as the product of $\mathrm{R}_{\mathrm{aw}}$ and $F \mathrm{FC}_{\mathrm{box}}$; $S G_{a w}$ was derived as the reciprocal from $S R_{a w}$, both for $R_{a w ~} t$ and $\mathbf{R}_{\text {aw } 0.5 \text {. }}$

(5) In six asthmatic children, the changes of $F R C_{b o x}$ and of resistance and conductance values were analysed in 22 inhalation tests with provoked bronchial obstruction. A test was called positive if there was a rise of $R_{a w} t$ of at least $50 \%$ of the initial value or if a rise of $R_{a w}$ of at least $25 \%$ was combined with an increase of $\mathrm{FRC}_{\mathrm{box}}$ of at least $25 \%$. This definition takes into consideration the spontaneous intra-individual variation of $R_{a w}$ values-the

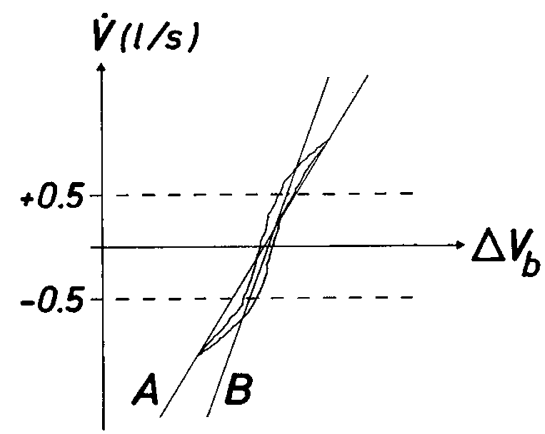

Fig. 1. Determination of $\operatorname{tg} \beta=\Delta \mathrm{V}_{\mathrm{b}} / \dot{\mathrm{V}}$ for calculation of $\mathrm{R}_{\mathrm{aw}}$. $\dot{\mathrm{V}}$, respiratory flow; $\Delta \mathrm{V}_{\mathrm{b}}$, volume changes of the plethysmographic box. For $\mathrm{R}_{\mathrm{aw}}$ t, the line connecting the points of maximum flow is used $(A)$. For $\mathrm{R}_{\mathrm{aw} \text { 0.5. }}$, the line is drawn through the points at an inspiratory and expiratory flow of 0.5 liter/sec. If there is a loop, the bisecting points of the $\Delta V_{b}$ difference at 0.5 liter $/ \mathrm{sec}$ are used $(B)$.

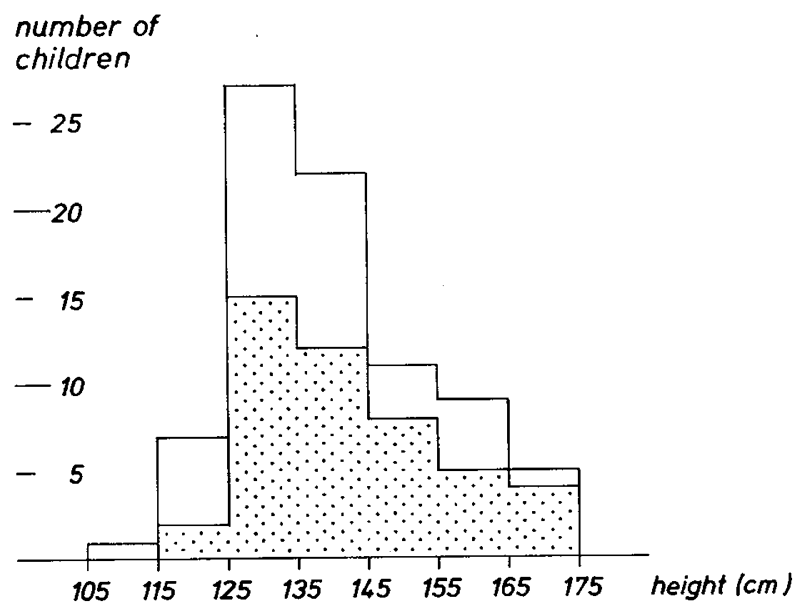

Fig. 2. Distribution of standing height of 82 healthy boys and girls in whom $R_{\text {aw }}$ was measured. The dotted area represents the 46 children in whom also calculation of $R_{\text {aw } 0.5}$ was possible. breath-to-breath coefficient of variation of 6 to 10 breathing cycles in asthmatic children before provocation was $19.5 \%$ - and the observation that an increase of $\mathrm{FRC}_{\text {box }}$ suggests peripheral bronchial obstruction (15).

\section{RESULTS}

The results of the measurements and calculations are as follows.

(1) Double logarithmic (or power) regression equations for

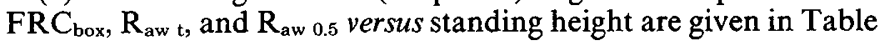
1. $\mathrm{FRC}_{\text {box }}$ shows a significant difference between boys and girls regarding the distance of the regression lines $(P<0.001)$, but not regarding the slope. $\mathrm{FRC}_{\mathrm{box}}$ increases with standing height at a high correlation.

For $\mathrm{R}_{\mathrm{aw}} \mathrm{t}$, data has been published previously (14). There is no significant difference between boys and girls $(P>0.2) ; \mathrm{R}_{\mathrm{aw}} \mathrm{t}$ decreases with increasing standing height, the residual standard deviation is considerable.

In healthy children, $\mathbf{R}_{\mathrm{aw} 0.5}$ is significantly smaller than $\mathbf{R}_{\mathrm{aw}} \mathrm{t}$. Comparing the individual $\mathrm{R}_{\mathrm{aw}} 0.5$ and $\mathrm{R}_{\mathrm{aw}} \mathrm{t}$ values $(n=46)$, there is a mean difference of $10.3 \pm 10.1 \%$ of $\mathrm{R}_{\text {aw } t}(P<0.001)$.

For further interpretation, $R_{a w} t$ values of 82 children were compared to $R_{\text {aw } 0.5}$ values of the 46 children selected from the 82 . This procedure seems to be justified because there is no significant difference between the $R_{a w}$ regression lines of 82 and of 46 children concerning the slope or the distance. But, the correlation coefficient is higher and residual standard deviation is smaller in

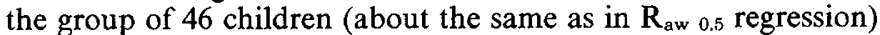
as a consequence of selection.

The mean intra-individual standard deviations (coefficients of variation) of three to five successive and nonselected respiratory cycles of $R_{a w 0.5}$ and $R_{a w ~}$ in the same group of 46 children are

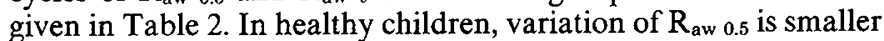
than of $R_{a w ~ t}$.

(2) Double logarithmic regression equations for $G_{a w} t$ and $\mathrm{G}_{\mathrm{aw}} 0.5$ versus standing height are given in Table 1 . Because in double logarithmic regression the equation for reciprocal values is the same as for the original values except for the signs, $G_{a w}$ from the $G_{a w}$ regression is the same as $G_{a w}$ calculated on $R_{a w}$ from the $R_{a w}$ regression equation, which is not true in linear regression. $\mathrm{G}_{\mathrm{aw}}$ increases with standing height. There is a significant differ-

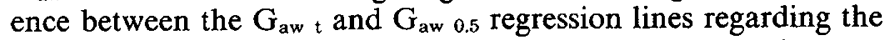
slope $(P<0.001)$ and the distance $(P<0.01) . \mathrm{G}_{\text {aw } 0.5}$ values are higher than $G_{a w}$ values, the difference being more distinct in taller children (5.8\% of $\mathrm{G}_{\mathrm{aw}} \mathrm{t}$ at $120 \mathrm{~cm}$ standing height, $14.3 \%$ at $160 \mathrm{~cm}$ ).

(3) Because there is a significant difference between boys and girls for $F R C_{b o x}$, regression equations and mean values of $S_{2}$ and $S_{a w}$ were considered for boys and girls separately and together. There is no significant correlation to standing height: $\mathrm{SR}_{\mathrm{aw}}$ and $\mathrm{SG}_{\mathrm{aw}}$ can be considered to be constant in children.

The geometric mean of $\mathrm{SR}_{\mathrm{aw} t}$ is $7.08 \mathrm{hPa} \cdot \mathrm{sec}$ for boys and girls together, the upper $95 \%$ confidence limit is $13.5 \mathrm{hPa} \cdot \mathrm{sec}$. In boys alone, the mean value is $7.57 \mathrm{hPa} \cdot \mathrm{sec}(95 \%$ limit $14.19 \mathrm{hPa} \cdot \mathrm{sec})$, in girls $6.48 \mathrm{hPa} \cdot \mathrm{sec}(95 \%$ limit $12.24 \mathrm{hPa} \cdot \mathrm{sec})$. $\mathrm{SR}_{\mathrm{aw}} \mathrm{t}$ is significantly smaller in girls than in boys $(P<0.05)$. For $\mathrm{SR}_{\mathrm{aw}} 0.5$, boys and girls together, the geometric mean value is $6.46 \mathrm{hPa} \cdot \mathrm{sec}$ and is not significantly smaller than that of $\mathrm{SR}_{\mathrm{aw}} \mathrm{t}(P>0.05)$.

The geometric mean value of $S_{a_{a w}}$ for boys and girls together is $0.141 \mathrm{hPa}^{-1} \cdot \mathrm{sec}^{-1}$ (lower $95 \%$ limit $0.074 \mathrm{hPa} \mathrm{Pa}^{-1} \cdot \mathrm{sec}^{-1}$ ), for boys alone it is $0.132 \mathrm{hPa}^{-1} \cdot \mathrm{sec}^{-1}\left(95 \%\right.$ limit $\left.0.070 \mathrm{hPa}^{-1} \cdot \mathrm{sec}^{-1}\right)$, and for girls $0.154 \mathrm{hPa}^{-1} \cdot \mathrm{sec}^{-1}\left(95 \%\right.$ limit $\left.0.082 \mathrm{hPa}^{-1} \cdot \mathrm{sec}^{-1}\right)$, the difference between the mean values of boys and girls being significant $(P<0.05)$. For $\mathrm{SG}_{\mathrm{aw} 0.5}$, boys and girls together, the geometric mean value is $0.155 \mathrm{hPa}^{-1} \cdot \mathrm{sec}^{-1}$ and is not significantly higher than that of $\mathrm{SG}_{\mathrm{aw} t}(P>0.05)$.

(4) Except for one test; all the provocation tests are positive according to the definition from the rise in $R_{a w} t$ alone. The difference between $R_{a w} 0.5$ and $R_{a w ~} t$ is more distinct before provocation (at a mean of $33.2 \pm 10.0 \%$ of $R_{a w} t$ ) than during 
Table 1. Regression equations for $F R C_{b o x}, R_{a w \iota}, R_{a w 0.5}, G_{a w ~}$, and $G_{a w 0.5}$ versus standing height ${ }^{1}$

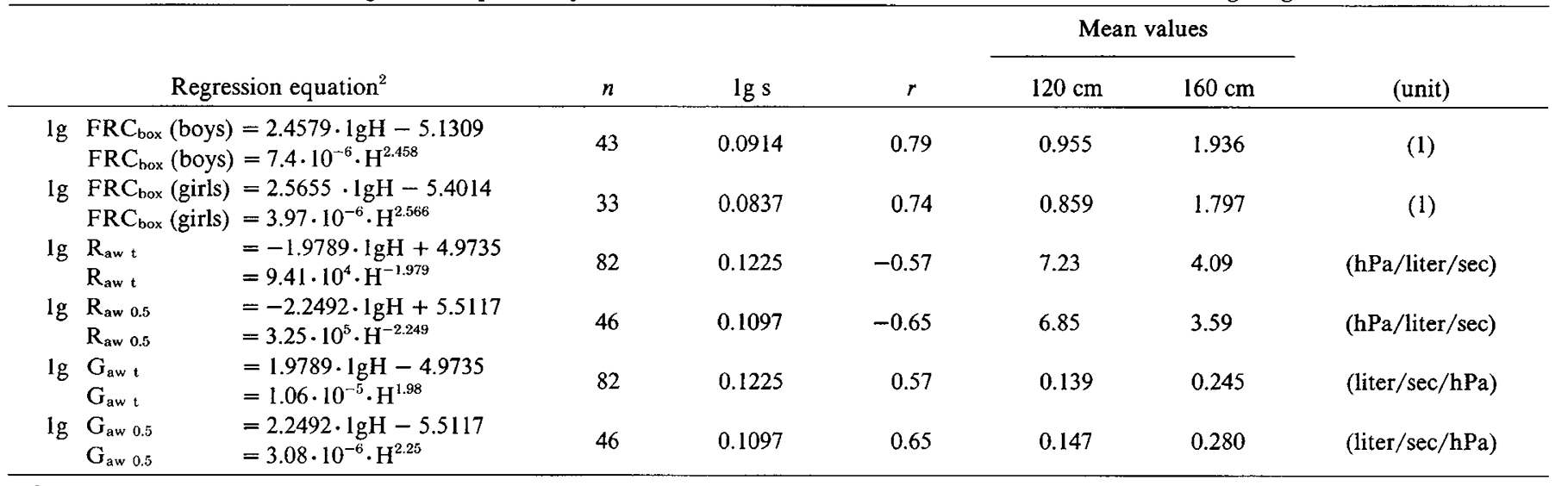

'Abbreviation: $\mathrm{n}$, number of children investigated; $\mathrm{s}$, residual standard deviation; $r$, coefficient of correlation; and $\mathrm{H}$, standing height in $\mathrm{cm}$.

${ }^{2}$ Except for $\mathrm{FRC}_{\text {box }}$, regression equations are for boys and girls together.

Table 2. Coefficients of variation (mean intra-individual standard deviation of three to five successive and non-selected respiratory cycles) of $R_{\text {aw } \iota}$ and $R_{\text {aw } 0.5}$ in healthy and in asthmatic children before provocation and during provoked bronchial obstruction

\begin{tabular}{lcc}
\hline & \multicolumn{2}{c}{ Coefficient of variation } \\
\cline { 2 - 3 } & $\mathrm{R}_{\mathrm{aw}} \mathrm{t}$ & \multicolumn{1}{c}{$\mathrm{R}_{\mathrm{aw}} 0.5$} \\
\hline Healthy children & $13.6 \pm 8.6 \%$ & $9.3 \pm 6.1 \%$ \\
& $(2.4-42.7 \%)$ & $(0.1-20.8 \%)$ \\
Asthmatic children before provocation & $5.3 \pm 2.8 \%$ & $11.5 \pm 7.3 \%$ \\
& $(2.0-13.9 \%)$ & $(4.3-32.7 \%)$ \\
Asthmatic children during provoked & $3.4 \pm 1.9 \%$ & $6.6 \pm 3.1 \%$ \\
bronchial obstruction & $(1.4-8.3 \%)$ & $(1.8-12.2 \%)$ \\
\hline
\end{tabular}

positive reaction $(23.1 \pm 7.4 \%)$. The mean rise of $R_{a w ~}$ is $113 \%$, for $R_{a w} 0.5$ it is $154 \%$, the \% being only in 4 tests slightly higher in $\mathbf{R}_{\mathrm{aw} t}$ than in $\mathbf{R}_{\mathrm{aw} \mathrm{0.5}}$. The mean changes of the different parameters in $\%$ of the initial value are summarized in Table 3. Standard deviations in \% of the mean changes (coefficients of variation) do not differ for the terminal and the fixed-flow type of interpretation. Individual changes in $\mathbf{S R}_{\mathrm{aw}} \mathrm{t}$ are shown in Figure 3.

The mean intra-individual standard deviation of $R_{a w} t$ and

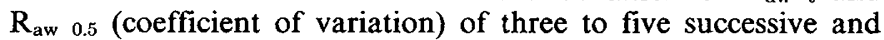
nonselected respiratory cycles in this group of asthmatic children before and during positive provocation is given in Table 2 .

\section{DISCUSSION}

(1) Comparison to literature. There are some publications compiling predicted values of plethysmographic data including $\mathrm{FRC}_{\text {box }}$ and $\mathrm{R}_{\mathrm{aw}}$ from different authors $(1,13,21,25)$. But even the comprehensive review by Michaelson and co-workers (21) omits some important publications and quotes only two authors who measured $R_{a w}$ during spontaneous breathing. In order to compare our results for $R_{a w}, S R_{a w}, G_{a w}$, and $S_{a w}$ to those reported in the literature, we compiled the data available (Table 4). Only investigations with larger numbers were included. $\mathrm{FRC}_{\mathrm{box}}$ is added in order to supplement information on resistance. Our data on $\mathrm{FRC}_{\text {box }}$ is in line with that of other authors except for Haluszka (13) whose values are substantially higher.

The methods of determination of $R_{a w}$ differ concerning the type of breathing, the graphical interpretation of the resistance curve, the formula for calculating $\mathbf{R}_{\mathrm{aw}}$, and the statistical approach. Moreover, some authors did not state their method exactly. Because there is no standardization of plethysmography, comparability of predicted values is limited.

The problem of differences in $R_{a w}$ measured during panting
Table 3. Mean change of different parameters in 22 positive

\begin{tabular}{|c|c|c|c|c|c|}
\hline & $\bar{\Delta}(\%)$ & SD & $\mathrm{VC}(\%)$ & range $(\%)$ & $t$ test $^{2}$ \\
\hline $\mathrm{FRC}_{\text {box }}$ & +17 & \pm 12 & 71 & -13 to +39 & \\
\hline$R_{\text {aw } t}$ & +113 & \pm 73 & 64 & +28 to +332$\}$ & $P<0001$ \\
\hline $\mathbf{R}_{\mathrm{aw} 0.5}$ & +154 & \pm 95 & 62 & +18 to +414$\}$ & $P<0.001$ \\
\hline $\mathrm{G}_{\mathrm{aw} t}$ & -49 & \pm 13 & 25 & -22 to -77$\}$ & \\
\hline $\mathrm{G}_{\text {aw } 0.5}$ & -56 & \pm 14 & 26 & -16 to -81$\}$ & $P<0.01$ \\
\hline $\mathrm{SR}_{\mathrm{aw} t}$ & +149 & \pm 82 & 55 & +46 to +280$\}$ & $P<0,001$ \\
\hline $\mathbf{S R}_{\text {aw } 0.5}$ & +193 & \pm 111 & 58 & +52 to +312$)$ & \\
\hline $\mathrm{SG}_{\mathrm{aw} \mathrm{t}}$ & -56 & \pm 12 & 21 & -31 to -80$\}$ & \\
\hline $\mathrm{SG}_{\mathrm{aw} 0.5}$ & -62 & \pm 13 & 21 & -34 to -85$\}$ & $r<0.01$ \\
\hline
\end{tabular}

${ }^{1} \bar{\Delta}$, mean change in $\%$ of initial value; S.D., standard deviation; and $\mathrm{CV}$, coefficient of variation (S.D. in \% of $\bar{\Delta}$ ).

${ }^{2}$ Paired $t$ test shows significantly higher changes for $\mathrm{R}_{\mathrm{aw}} 0.5$ and its derivates.

and during quiet breathing is very complex (2). $R_{a w}$ during panting may be smaller or higher than $R_{a w}$ during quiet breathing depending on frequency, flow rate, and normal or abnormal status of the lungs. Therefore, if the equipment of the plethysmograph allows, $\mathrm{R}_{\mathrm{aw}}$ should be measured during quiet breathing.

$R_{a w}$ at fixed flow rates is definitely smaller than $R_{a w}$ over total flow range, in the present results at a mean of $10.3 \%$. If only the inspiratory resistance is measured, the difference is even more pronounced $(9,22)$.

Differences due to different opinions on correction for deadspace volume and resistance of the apparatus are especially important in smaller children because of higher $R_{a w}$ values and larger dead-space volume in relation to lung volumes. Because there is no correction of $\operatorname{tg} \alpha$ for dead-space in Matthys' (20) formula for the calculation of $R_{a w}, R_{a w}$ was measured smaller than it would have been with a correction: the difference is about 5$11 \%$, depending on height.

We prefer $R_{a w}$ to $G_{a w}$ for reasons discussed by other authors (4, 7). For comparison $\mathrm{G}_{\mathrm{aw}}$ values are given, too.

Some authors agree on $\mathrm{R}_{\mathrm{aw}}$ with values around $5 \mathrm{hPa} /$ liter/sec at $120 \mathrm{~cm}$ standing height and around $2.5 \mathrm{hPa} / \mathrm{liter} / \mathrm{sec}$ at $160 \mathrm{~cm}$. Weng and Levison (27) and Kamel and co-workers (19) found higher values in smaller children. The values of Godfrey and coworkers (11) are generally not accepted because they are far below the values observed by all the other investigators, probably due to some systematic error (13). Dab and Alexander (6) reported values much higher than all the others. Düggelin and Bühlmann (9) calculated $\mathbf{R}_{\mathrm{aw}}$ at a high flow rate separately for inspiration and expiration. Inspiratory $R_{a w}$ is in line with the above-mentioned authors, combined values for a whole breathing cycle would 


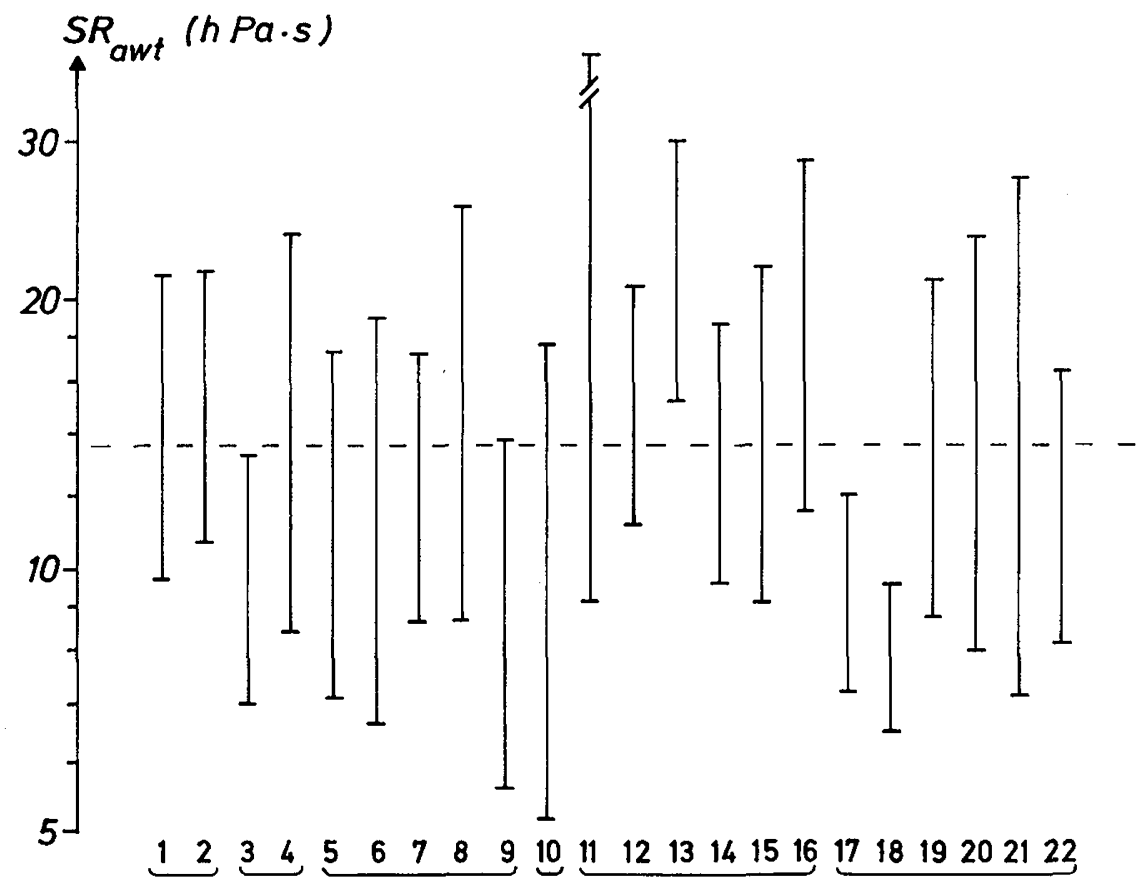

Fig. 3. Changes of $S R_{a w} t$ in 22 positive inhalation tests. The tests were considered positive from the change in $R_{a w} t$ and $F R C_{b o x}(s e e$ text). The illustration shows the rise in $\mathrm{SR}_{\mathrm{aw}} \mathrm{t}$ from initial value (lower limit) to the value during positive reaction (upper limit). The broken line represents the upper $95 \%$ confidence limit of $\mathrm{SR}_{\mathrm{aw}} \mathrm{t}$ for boys and girls together. R.E. (1 and 2), T.B. (3 and 4), F.B. (5-9), and S.B. (10), are boys; M.B. (11-16) and C.A. $(17-22)$ are girls.

probably be similar to our values. Dab and Alexander, Düggelin and Bühlmann, and ourselves are using a body plethysmograph of the same design (29). Dab and Alexander (6), whose $R_{a w}$ values are the highest in literature, even went so far as to postulate that every laboratory should establish its own predicted values, which seems quite reasonable in face of the lack of standardization.

As with $\mathbf{R}_{\mathrm{aw}}$, there is good agreement among many authors on $\mathrm{SR}_{\mathrm{aw}}$ and $\mathrm{SG}_{\mathrm{aw}}$ results, too, with mean values around $5 \mathrm{hPa} \cdot \mathrm{sec}$ and $0.2 \mathrm{hPa}^{-1} \cdot \mathrm{sec}^{-1}$, respectively. Values of Cogswell and coworkers (5) and Haluszka (13) are higher (probably because of higher $\mathrm{FRC}_{\text {box }}$ values) with mean values around $7 \mathrm{hPa} \cdot \mathrm{sec}$. They agree with our results. Dab and Alexander (6) reported an even higher $\mathrm{SR}_{\mathrm{aw}}$ mean value of $10 \mathrm{hPa} \cdot \mathrm{sec}$.

Because of log-normal distribution of $S_{a w}$ values (24), the geometric mean should be used, which is smaller than the arithmetic mean (in our study 5\%), whereas the geometric upper $95 \%$ confidence limit is higher (in our study $11 \%$ ). Calculation of $\mathrm{SR}_{\mathrm{aw}}$ mean value and upper $95 \%$ limit as the reciprocal of $\mathrm{SG}_{\mathrm{aw}}$ is correct only if the geometric mean is used, otherwise $\mathbf{S R}_{\text {aw }}$ mean value and upper 95\% limit will be underestimated. Geometric mean values are given only by Pelzer and Thomson (24), who reported values in adults, by Dab and Alexander (6), and by ourselves. Upper $95 \%$ limits differ considerably among the investigations.

(2) Comparison of $R_{a w} t$ and $R_{a w} 0.5$. According to Ferris and coworkers (10), in the range of flow of \pm 2 liter/sec (in adults) the non-linearity of $R_{a w}$ is mainly contributed by the upper airways, whereas the resistance of the intrathoracic airways is linear. The highest $\mathbf{R}_{a w}$ values during a breathing cycle are measured at the points of maximum inspiratory and expiratory flow rates where turbulent flow in the upper airways can be suspected. The variation of upper airway resistance has been related to changes in

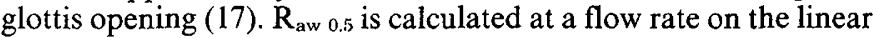
part of the resistance curve; it can therefore be expected that $R_{a w} 0.5$ represents better than $R_{a w}$ the resistance of the intrathoracic airways. Our observation that the intra-individual coefficient of variation in healthy children is smaller for $R_{a w} 0.5$ than for $R_{a w ~ 0.5}$ than for $R_{a w ~} t$ seems to confirm this conclusion.

In the provocation tests, the difference between $R_{a w} 0.5$ and
$\mathrm{R}_{\mathrm{aw}} \mathrm{t}$ is more evident before provocation than during positive reaction, and thus the rise in $R_{a w ~ 0.5}$ is higher than in $R_{a w ~}$ (Table

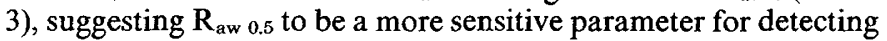
bronchial obstruction. This, too, can be interpreted as a better representation of the intra-thoracic resistance.

From these data, $R_{a w 0.5}$ seems to be preferable to $R_{a w}$. The applicability of $R_{a w} 0.5$ is limited because some children do not reach a sufficient flow rate in inspiration and expiration during quiet breathing. Children would have to be stimulated to breath at a slightly higher frequency. This was done by Haluszka (13) even for measurement of $R_{a w} t$. It can be assumed that little stimulation of breathing will not alter $R_{a w} 0.5$ as much as it would $\mathrm{R}_{\mathrm{aw}} \mathrm{t}$; moreover, in clinical investigation we are observing sufficient flow rates during quiet breathing without stimulation in almost all children.

In contrast to healthy children, the variation coefficient of $R_{\text {aw } t}$ in the few asthmatic children investigated is smaller than that of $R_{a w} 0.5$ (Table 2). First, this might be caused partly by reading errors occurring in the $R_{a w} 0.5$ determination. Because in asthmatic children the resistance curves are somewhat looped, the auxiliary line has to be drawn through the bisecting points at a flow of 0.5 liter/sec (Fig. 1). These points cannot be determined as exactly as the points of terminal flow; moreover, with a certain graphical error at the level of $0.5 \mathrm{liter} / \mathrm{sec}$, the slope of that line is more influenced than with the same error at terminal flow level. Second, the variation of the glottis opening seems to be less important in asthmatic children well trained in the laboratory methods than in healthy children. Although our group of asthmatic children is not comparable to that of healthy children because of the small number and lack of normal distribution, the discrepancy in the variation coefficients is not fully intelligible and deserves further investigation.

(3) Evaluation of inhalation provocation tests. According to the above stated definition, a provocation test would be positive if

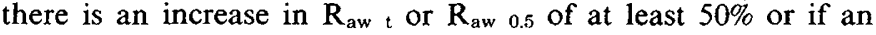

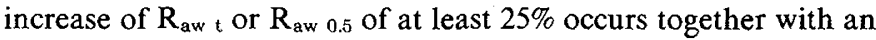
increase in $F_{R C_{b o x}}$ of $25 \%$ or more. Using $G_{a w}$, there must be a fall of at least $33 \%$ or of at least $20 \%$ if combined with an increase in $\mathrm{FRC}_{\mathrm{box}}$ of $25 \%$ or more. With these definitions, one of the tests 
Table 4. Values from literature for $F R C_{b o x}, R_{a w}, S R_{a w}, G_{a w}$, and $S G_{a w}$ in healthy children

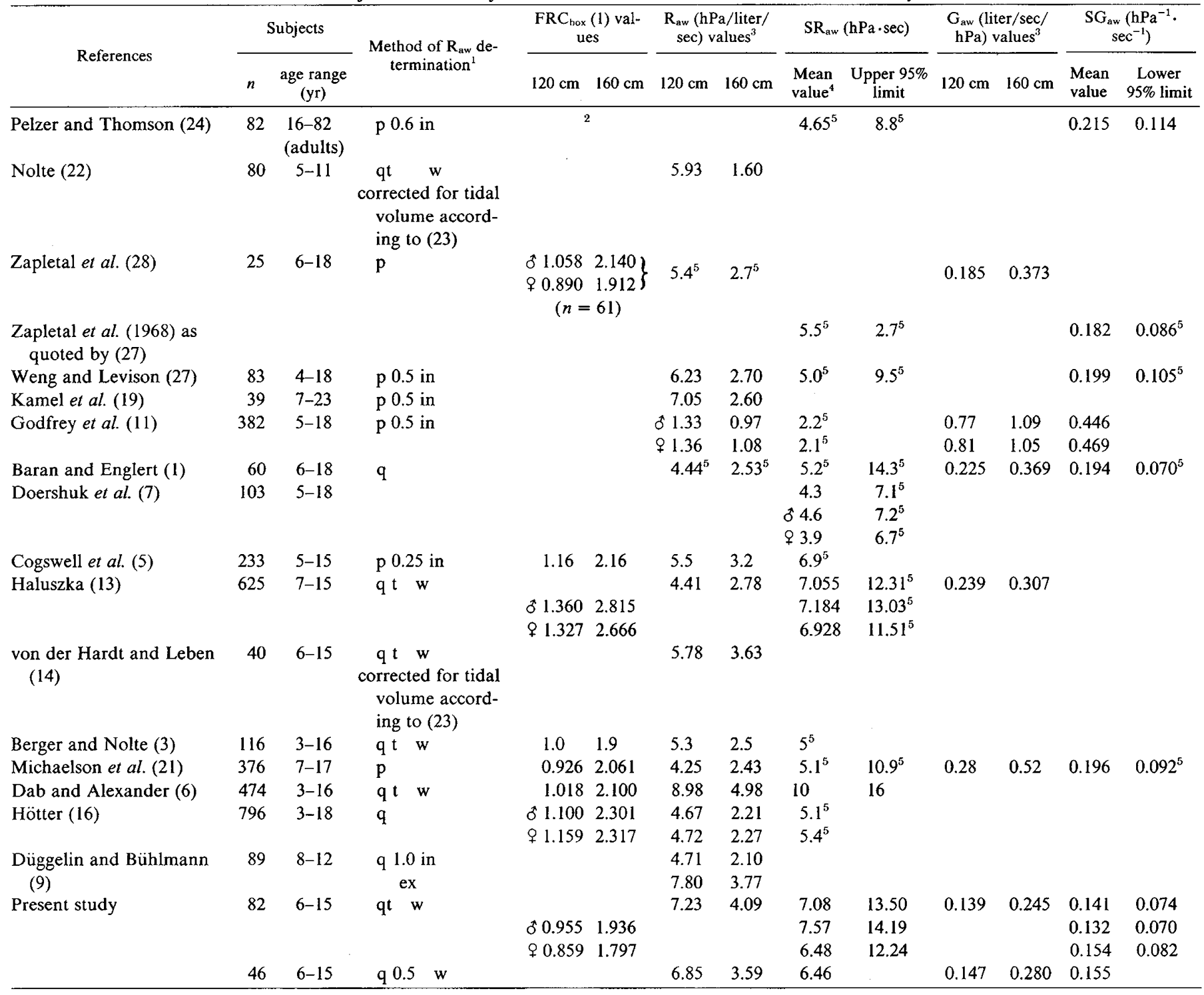

\footnotetext{
${ }^{1}$ Concerning the method of $R_{a w}$ determination, only breathing pattern (p, panting and q, quiet breathing), flow rate at which $R_{a w}$ is calculated (liter/ sec; $t$, terminal $R_{a w}$ ), and respiratory phase (in, only inspiratory $R_{a w}$; ex, only expiratory $R_{a w}$; and $w$, whole breathing cycle) are stated; for further details see the original literature.

${ }^{2} \mathrm{Blank}$ spaces indicate that information is not available. If not stated otherwise, values are for boys and girls together. Pressure units $\mathrm{cmH}_{2} \mathrm{O}$ and $\mathrm{hPa}$ $\left(1 \mathrm{cmH}_{2} \mathrm{O}=0.98 \mathrm{hPa}\right.$ ) were considered to be equal.

${ }^{3}$ For $R_{a w}$ and $G_{a w}$, predicted values at $120 \mathrm{~cm}$ and $160 \mathrm{~cm}$ standing height were calculated from regression equations or read from illustrations to indicate the degree of change with height. Both heights are within the height range of most of the investigations.

${ }^{4}$ If the authors did not provide information on $\mathrm{SR}_{\mathrm{aw}}, \mathrm{SR}_{\mathrm{aw}}$ mean values were calculated or estimated from given data where possible; of course, estimation of $S R_{a w}$ from $F R C_{\text {box }}$ and $R_{a w}$ predicted values is only a rough approximation. Upper $95 \%$ confidence limits were estimated as mean value plus 2 S.D.

${ }^{5}$ All data not originally provided by the authors.
}

would not have been considered to be positive if $R_{a w ~ 0.5}$ or $G_{a w 0.5}$ were used (the rise in $R_{a w ~ 0.5}$ was only $18 \%$, whereas in $R_{a w ~}$ it was $28 \%)$.

If only $\mathrm{R}_{\mathrm{aw}}$ (or $\mathrm{G}_{\mathrm{aw}}$ ) is looked at, only obstruction in the more central airways becomes apparent, whereas changes in $\mathrm{FRC}_{\mathrm{box}}$ also suggest obstruction of the more peripheral airways (15). Because $F R C_{\text {box }}$ is included in $\mathrm{SR}_{\mathrm{aw}}$ and $\mathrm{SG}_{\mathrm{aw}}$, a positive reaction can be recognized by the change in $S_{a w}$ or $S G_{a w}$ alone. These parameters are more sensitive in detecting bronchial obstruction than $R_{a w}$ or $G_{a w}$ alone (Table 3 ) with the additional advantage of being independent of standing height. They are especially helpful in determining whether the respiratory system is in condition to be challenged or not. We suggest not to perform a provocation test if the initial $\mathrm{SR}_{\mathrm{aw}}$ or $\mathrm{SG}_{\mathrm{aw}}$ value is beyond the $95 \%$ confidence limit, which would indicate bronchial obstruction. For considering a test positive, the $\mathrm{SR}_{\mathrm{aw}}$ value during provocation must rise above (or $\mathbf{S G}_{\mathrm{aw}}$ fall below) the $95 \%$ limit (12). But the rise in $\mathbf{S R}_{\mathrm{aw}}$ must be at least $50 \%$ of the initial value in order to avoid falsely positive tests due to spontaneous intra-individual changes; if $\mathrm{G}_{a w}$ is used, there has to be a fall of at least $33 \%$.

In Figure 3, for the 22 positive provocation tests, only the change in $\mathrm{SR}_{\text {aw } t}$ is shown. For practical reasons, the upper $95 \%$ confidence limit for boys and girls together is used, although there was a significant difference between the mean values of boys and girls separately. According to our suggestion, one of the tests would not have been continued because the initial $\mathrm{SR}_{\mathrm{aw}}$ value was above the $95 \%$ limit in a child with otherwise smaller $\mathbf{S R}_{\mathrm{aw}}$ values (number 13 in Fig. 3). In three tests (number 3, 17, and 18 in Fig. 
3 ), the result would not have been positive because the $95 \%$ limit was not reached, although there was a sufficient rise in $\%$ of the initial $\mathrm{SR}_{\mathrm{aw}}$ value (except for $\mathrm{SR}_{\mathrm{aw}} \mathrm{t}$ in one test: number 18 in Fig. 3 , there was a decrease in $\mathrm{FRC}_{\mathrm{box}}$ ). Continuing the challenge with higher concentrations of the allergen, a positive result would have been to be expected.

In the small group of asthmatic children investigated, calculation of $\mathbf{R}_{\mathrm{aw}} 0.5$ improves the sensitivity in detecting bronchial obstruction. The mean rise (in \%) of $\mathrm{R}_{\text {aw } 0.5}$ during positive reaction equals that of $S R_{a w}$, the mean fall of $G_{a w 0.5}$ that of $S G_{a w ~}$, $\mathrm{SR}_{\mathrm{aw}} 0.5$ and $\mathrm{SG}_{\mathrm{aw}} 0.5$ are even more sensitive (Table 3). Judging from the change in $\%$ of the initial value, the most sensitive parameter for detecting bronchial obstruction is $\mathbf{S R}_{\mathrm{aw}} 0.5$. For positive reaction, the range of interest is in the borderline area of the definition, not far above it. Therefore, even though the change of $\mathrm{G}_{\mathrm{aw}}$ or $\mathrm{SG}_{\mathrm{aw}}$ in \% is not as impressive as of $\mathrm{R}_{\mathrm{aw}}$ or $\mathrm{SR}_{\mathrm{aw}}$ (e.g., an $R_{a w}$ increase of $300 \%$ instead of $100 \%$ results in a $G_{a w}$ decrease of only $75 \%$ instead of $50 \%$ ), $S_{\mathrm{aw}_{0.5}}$ equals $\mathrm{SR}_{\mathrm{aw} 0.5}$ regarding the sensitivity.

Comparing asthmatic children before and during positive provocation reaction, the coefficients of variation for both $R_{a w} 0.5$ and $R_{\text {aw } t}$ become distinctly smaller under positive reaction (Table 2 ). This can be explained by a smaller influence of upper airway resistance during hyperventilation $(17,18)$. A similar observation was reported and discussed by von der Hardt and co-workers (15) who found a coefficient of variation in $R_{a w}$ of $19.5 \%$ before provocation and of $10.1 \%$ during bronchial obstruction. The present data show distinctly smaller coefficients of variation.

\section{REFERENCES AND NOTES}

1. Baran, D. and Englert, M.: La conductance des voies aériennes chez l'enfant et l'adolescent normaux. Bull. Physio-Path. Resp., 7: 125 (1971).

2. Barter, C. E. and Campbell, A. H.: Comparison of airways resistance measurements during panting and quiet breathing. Respiration, 30: 1 (1973).

3. Berger, D. and Nolte, D.: Bodyplethysmographische Sollwerte für Kinder. Prax. Pneumol. 31: 600 (1977).

4. Clement, J. and van de Woestijne, K. P.: Resistance or conductance? Compliance or elastance? J. Appl. Physiol., 30: 437 (1971)

5. Cogswell, J. J., Hull, D., Milner, A. D., Norman, A. P., and Taylor, B.: Lung function in childhood. 2. Thoracic gas volumes and helium functional residual capacity measurements in healthy children. Brit. J. Dis. Chest, 69: 118 (1975). 3. Measurement of airflow resistance in healthy children. Brit. J. Dis. Chest, 69: 177 (1975).

6. Dab, I. and Alexander, F.: Lung function measured with a whole body plethysmograph. Standard values for children and young adults. Acta Paediatr. Belg. 32: 259 (1979)

7. Doershuk, C. F., Fisher, B. J., and Matthews, L. W.: Specific airway resistance from the perinatal period into adulthood. Amer. Rev. Resp. Dis., 109: 452 (1974).

8. DuBois, A. B., Botelho, S. Y., and Comroe, J. H., Jr.: A new method for measuring airway resistance in man using a body plethysmograph: values in normal subjects and in patients with respiratory disease. J. Clin. Invest., 35: 327 (1956).
9. Düggelin, S. and Bühlmann, A. A.: Lungenvolumina und Atemwegwiderstände bei gesunden Zürcher Schulkindern-Normalwerte. Helv. Paediat. Acta, 35: 21 (1980).

10. Ferris, B. G., Jr., Mead, J., and Opie, L. H.: Partitioning of respiratory flow resistance in man. J. Appl. Physiol., 19: 653 (1964).

11. Godfrey, S., Kamburoff, P. L., and Nairn, J. R.: Spirometry, lung volumes and airway resistance in normal children aged 5 to 18 years. Brit. J. Dis. Chest, 64: 15 (1970).

12. Gonsior, E., Meier-Sydow, J., and Thiel, C.: Routine application of body plethysmography in bronchial allergen challenge. Bull. Physio-path. Resp., 8: 519 (1972).

13. Haluszka, $\mathbf{J}$.: Application of the whole body plethysmography in examination of respiratory system in children. Predicted values, interrelations, methodical suggestions. National Institute for Mother and Child, Branch in Rabka, Poland (translated from Polish by Maria Teutsch M.A.). Rabka (1976).

14. von der Hardt, H. and Leben, M.: Bodyplethysmography in healthy children. Measurement of intrathoracic gas volume and airway resistance. Europ. J. Pediatr., 124: 13 (1976).

15. von der Hardt, H., Miels, M., and Geubelle, F.: Bronchial inhalation challenge by plethysmography in asthmatic children. Respiration, 34: 9 (1977).

16. Hötter, G. J.: Spirographische, bodyplethysmographische und gasanalytische Sollwerte bei Kindern und Jugendlichen. Prax. Pneumol., 33: 1178 (1979).

17. Hyatt, R. E. and Wilcox, R. E.: Extrathoracic airway resistance in man. J. Appl. Physiol., 16: 326 (1961).

18. Jaeger, M. J. and Matthys, H.: The pattern of flow in the upper human airways. Respiration Physiol., 6: 113 (1968).

19. Kamel, M., Weng, T. R., Featherby, E. A., Jackman, W. S., and Levison, H.: Relationship of mechanics of ventilation to lung volumes in children and young adults. Scand. J. Resp. Dis., 50: 125 (1969).

20. Matthys, H.: Lungenfunktionsdiagnostik mittels Ganzkörperplethysmographie. Chpt. 2. (Stuttgart-New York, F. K. Schattauer 1972)

21. Michaelson, E. D., Watson, H., Silva, G., Zapata, A., Serafini-Michaelson, S. M., and Sackner, M. A.: Pulmonary function in normal children. Bull. Europ. Physio-path. Resp., 14: 525 (1978).

22. Nolte, D.: Der bronchiale Strömungswiderstand im Kindesalter. Klin. Wochenschr., 46: 783 (1968).

23. Nolte, D., Reif, E., and Ulmer, W. T.: Die Ganzkörperplethysmographie. Methodische Probleme und Praxis der Bestimmung des intrathorakalen Gasvolumens und der Resistance-Messung bei Spontanatmung. Respiration, 25: 14 (1968).

24. Pelzer, A. M. and Thomson, M. L.: Effect of age, sex, stature, and smoking habits on human airway conductance. J. Appl. Physiol., 21: 469 (1966).

25. Polgar, G. and Promadhat, V.: Pulmonary function testing in children: techniques and standards. Chpt. 5. (Philadelphia-London--Toronto, W. B. Saunders 1971).

26. Ulmer, W. T. and Reif, E.: Die obstruktiven Erkrankungen der Atemwege. Klinische Bedeutung und objektiver Nachweis mit der Ganzkörperplethysmographie. Dtsch. Med. Wochenschr., 90: 1803 (1965).

27. Weng, $\Upsilon$. R. and Levison, H.: Standards of pulmonary function in children. Amer. Rev. Resp. Dis., 99: 879 (1969).

28. Zapletal, A., Motoyama, E. K., van de Woestijne, K. P., Hunt, V. R., and Bouhuys, A.: Maximum expiratory flow-volume curves and airway conductance in children and adolescents. J. Appl. Physiol., 26: 308 (1969).

29. Pulmorex, Dr. Fenyves \& Gut, Basel, Switzerland.

30. Houston Instruments, Texas, USA.

31. Requests for reprints should be addressed to: M. Leben, Kinderklinik der Medizinischen Hochschule Hannover, K.-Gutschow-Straße 8, D-3000 Hannover 61 .

32. Received for publication April 22, 1982.

33. Accepted for publication August 19, 1982. 